\title{
An analytical approach to the $\beta$-phase coarsening behaviour in a thermally sprayed CoNiCrAlY bond coat alloy
}

\author{
H. Chen ${ }^{\mathrm{a}, *}$, Y. Q. Si ${ }^{\mathrm{a}}$ and D. G. McCartney ${ }^{\mathrm{b}}$
}

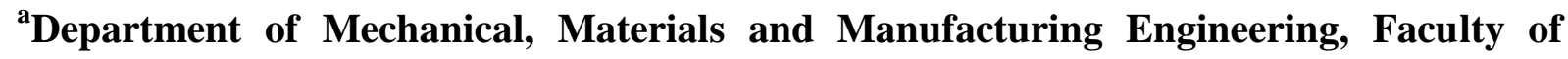
Science and Engineering, University of Nottingham Ningbo China, Ningbo 315100, China

${ }^{b}$ Advanced Materials Research Group, Faculty of Engineering, University of Nottingham, University Park, Nottingham NG7 2RD, UK

\begin{abstract}
This paper investigates the $\beta$-phase coarsening behaviour during isothermal heat treatment of free-standing CoNiCrAlY (Co-31.7\%Ni-20.8\%Cr-8.1\%Al-0.5\%Y, all in wt $\%)$ coatings prepared by high velocity oxy-fuel (HVOF) thermal spraying. The microstructure of the coatings was characterised using scanning electron microscopy with energy dispersive X-ray (EDX) analysis and electron backscatter diffraction (EBSD). It comprises a two phase structure of fec $\gamma$-Ni matrix and bcc $\beta$-NiAl precipitates. The volume fraction of the $\gamma-\mathrm{Ni}$ and the $\beta$-NiAl phases were measured to be around $70 \%$ and $30 \%$ respectively, with grain sizes varying largely from 0.5 to $2 \mu \mathrm{m}$ for both phases. Isothermal heat treatments of the freestanding coatings were carried out at $1100{ }^{\circ} \mathrm{C}$ for times up to $250 \mathrm{~h}$. The $\beta$-phase coarsening behaviour during isothermal heat treatments was analysed by quantitative metallography. It is shown that the coarsening behaviour of $\beta$ phase in the CoNiCrAlY alloy followed the classical Lifshitz-Slyozov-Wagner (LSW) theory of Ostwald ripening. By incorporating a dimensionless factor which correlates with volume fraction of the $\beta$ phase, a modified LSW model coupled with formulaic interfacial energy and effective diffusion coefficient of the
\end{abstract}


CoNiCrAlY alloy was utilised to interpret the coarsening behaviour of the $\beta$ phase. The coarsening rate coefficient obtained from the modified LSW model shows good agreement with the corresponding experimental result.

Keywords: HVOF spraying; MCrAlY; $\beta$-phase; Coarsening; Heat treatment; Diffusion

*Corresponding Author. Tel.: +86-574-88180000-8946; Fax: +86-574-88187462.

E-mail address: Hao.Chen@ nottingham.edu.cn 


\section{Introduction}

$\operatorname{MCrAlY}(\mathrm{M}=\mathrm{Co}, \mathrm{Ni}$ or a combination of the two $)$ are widely used as overlay coatings and as bond coats in thermal barrier coating (TBC) systems to protect high temperature components in turbine engines from harsh operating environments [1-8]. Depending on the composition, MCrAlY alloys are typically complex multi-phase materials and can comprise, for example, fcc $\gamma$-Ni and bec $\beta$-NiAl [9-14]. The mechanical properties of the MCrAlY coatings largely depend on the volume fraction and morphology of the $\beta$-phase precipitates [15-17]. During service, the coating oxidises and forms an outer layer of thermally grown oxides (TGO) [1820]. MCrAlY coatings exhibit their protective effect at elevated temperatures owing to the fact that aluminium from the Al-rich $\beta$-phase promotes a continuous oxide layer, predominantly alumina, to form at the coating surface [21-26]. Since MCrAlY coatings are exposed at high temperature for comparatively long period of time, the depletion and coarsening of the $\beta$ phase could occur. Such changes may result in substantial losses in the mechanical properties during service, leading to the catastrophic failure of the coating [27].

The oxidation and $\beta$-phase depletion have been extensively studied by others, e.g. [28-38]. In these research works, the emphasis has been on oxide growth, phase transformation and element diffusion, but specific concerns on the $\beta$-phase coarsening behaviour in the MCrAlY coating have not been addressed. With sufficient thermal energy, $\beta$ precipitates undergo coarsening, also termed Ostwald ripening, during which smaller particles dissolve and large particles grow [39]. The $\beta$-phase coarsening phenomenon has been observed in a few studies, but none of them investigated the coarsening characteristics [40-42]. Due to the importance of the particle sizes of $\beta$ phases for the mechanical properties of MCrAlYs, an understanding of the coarsening process of $\beta$ precipitates is essential for the design and application of MCrAlY coatings. The less computationally expensive method for predicting the $\beta$-phase growth, in its simplified form, is the mean field theory [43]. Lifshitz and Slyozov [44] and Wagner [45] (LSW) derived the first analytical description of particle coarsening in binary alloy systems, 
in which the predicted coarsening rate of the mean particle size is reported to be proportional to time $\mathrm{e}^{1 / 3}$. In recent decades, the theory proposed by LSW has been extended to multicomponent alloys such as Ni superalloys [46-52], Ti alloys [53-55] and other types of alloys [56-58]. However, application of LSW theory to MCrAlY alloys does not appear to have been previously reported.

Considering the significance of $\beta$-phase coarsening on the degradation of MCrAlY coatings, therefore, the aims of the work reported in this paper are to investigate specifically the kinetics of $\beta$-phase coarsening in free-standing CoNiCrAlY coatings during isothermal heat treatment and to develop a theoretical evaluation of the $\beta$-phase coarsening behaviour. A modified Ostward ripening model which accounts the interfacial energy, effective diffusion coefficient and the volume fraction of $\beta$ phase was employed to calculate the coarsening rate coefficient at $1100{ }^{\circ} \mathrm{C}$ with the aid of thermodynamics software Thermo-Calc using the TTNi7 thermodynamic database. In addition to calculated results, the coarsening behaviour was quantified through particle size measurements by image analysis. The work reported here is the first attempt on the $\beta$-phase coarsening behaviour in MCrAlY coatings.

\section{Materials and experimental procedure}

\subsection{Materials preparation and isothermal heat treatment}

The coatings used for isothermal heat treatments were prepared by high velocity oxy-fuel (HVOF) thermal spraying using powder with a nominal composition of Co-31.7\% Ni$20.8 \% \mathrm{Cr}-8.1 \mathrm{Al} \%-0.5 \% \mathrm{Y}$ (all in wt\%). The powder was obtained from Praxair (commercially available as CO-210-24) and had a size range $-45+20 \mu \mathrm{m}$ with a chemically analysed oxygen content of $0.037 \mathrm{wt} \% \mathrm{O}$. The coatings were deposited onto 800-grit ground mild steel substrates with dimensions $60 \times 25 \times 1.8 \mathrm{~mm}^{3}$ using a Met Jet III liquid fuel HVOF gun. The details of the spraying process are given in reference [59]. Coatings were sprayed to a thickness of approximately $0.5 \mathrm{~mm}$ and were then debonded from the ground substrate by 
bending around a mandrel. An initial vacuum heat treatment was given to the debonded coatings prior to isothermal heat treatment. Debonded coatings were heat treated in a vacuum with a nominal pressure of $6.0 \times 10^{-3}$ mbar at $1100{ }^{\circ} \mathrm{C}$ for $2 \mathrm{~h}$ followed by air cooling to replicate the initial heat treatment given to the bond coat material in conventional TBC manufacture. Previous work has demonstrated that the initial heat treatment has the effect of reducing any coating porosity to a minimal level and allows the $\beta$ phase to precipitate [42]. For isothermal heat treatments, heat treated samples were exposed in the vacuum at $1100{ }^{\circ} \mathrm{C}$ for $50 \mathrm{~h}, 75 \mathrm{~h}, 100 \mathrm{~h}$ and $250 \mathrm{~h}$ followed by natural air cooling.

\subsection{Material characterisation}

For microstructural observations, samples were mounted in a conductive resin and successively ground and polished to a $1 \mu \mathrm{m}$ surface finish. The microstructures of coating cross-sections before and after isothermal heat treatment were examined in a FEI XL 30 scanning electron microscope (SEM) operated at $20 \mathrm{kV}$. Backscattered electron (BSE) imaging was used to form images and semi-quantitative energy dispersive X-ray (EDX) analysis was also utilised for analysis of elemental compositions. Image analysis software, ImageJ [60], was used to measure the size of the $\beta$-phase particles and $\beta$-phase volume fractions. For each heat treatment condition, at least five micrographs were analysed to ensure the measuring reliability. SEM-based electron backscatter diffraction (EBSD) was carried out to investigate the grain morphology of coating cross-sections using a Zeiss $1530 \mathrm{VP}$ field emission gun SEM (Carl Zeiss, Inc, Mape, Grove, MN) with an EDAX Pegasus combined EBSD system (EDAX, Mahwah, NJ, USA). The EBSD patterns were recorded at an acceleration voltage of $20 \mathrm{kV}$ with a beam current of $26 \mathrm{nA}$ at a specimen tilt angle of $70^{\circ}$. EBSD maps were collected at a step size of $0.1 \mu \mathrm{m}$ for areas of $50 \mu \mathrm{m} \times 50 \mu \mathrm{m}$. The EBSD data acquisition and processing were performed using the EDAX OIM5 software suite. 


\section{Results and discussion}

\subsection{Microstructural analysis}

The microstructure of the vacuum heat treated CoNiCrAlY coating prior to isothermal heat treatment is shown in Fig. 1. It is evident from Fig. 1(a) that there is very little porosity apparent in the coating. Micron sized, dark contrast particles are also visible in Fig. 1(a). These tend to occur around the powder particle boundaries as either discrete particles or thin stringers. EDX analysis showed them to be rich in oxygen and aluminium and they are presumably aluminium oxides which have formed by oxidation of powders in-flight during the HVOF spraying process. From the figure it is clear that their volume fraction is less than 1\%. A two phase microstructure of this CoNiCrAlY coating, consisting of the light contrast fcc $\gamma$-Ni matrix phase and the dark contrast bcc $\beta-(\mathrm{Co}, \mathrm{Ni}) \mathrm{Al}$ phase, is shown in Fig. 2(b), which agrees well with previously reported work [15].

The volume fraction of the uniformly distributed $\beta$-phase was found to be $30 \% \pm 2 \%$ as measured by image analysis. A plot of phase mass fraction versus temperature obtained from Thermo-Calc is presented in Fig. 2 using the TTNi7 thermodynamic database. The alloy composition used is the initial powder composition $(\mathrm{Co}-31.7 \% \mathrm{Ni}-20.8 \% \mathrm{Cr}-8.1 \mathrm{Al} \%-0.5 \% \mathrm{Y}$, all in wt $\%$ ) and the phases considered in the Thermo-Calc calculation are liquid, fcc- $\gamma, \gamma^{\prime}, \sigma$ and $\beta$-NiAl. Due to the small amount of yttrium in the powder $(0.5 \mathrm{wt} \%)$ and its unavailability in the TTNi7 database, yttrium is thus neglected in the phase fraction calculations. Previous work [42] has shown that the measured phase compositions exhibit good agreements with the calculated phase compositions from the TTNi7 database and the interdiffusion modelling work between a Co-based MCrAlY coating and a Ni-based superalloy reported by Dahl et al. [61] has further demonstrated the suitability of this database for the CoNiCrAlY alloy used in this study. It can be seen that the expected constitution at $1100^{\circ} \mathrm{C}$ is $\gamma+\beta$. Since the volume data of the $\beta$-NiAl phase is not available in the TTNi7 database, the mass fractions of the $\gamma$ 
and $\beta$ phase, $f_{\gamma}^{M}$ and $f_{\beta}^{M}$, obtained from Thermo-Calc are converted to volume fractions, $f_{\gamma}^{V}$ and $f_{\beta}^{V}$, using the following equations,

$$
\begin{gathered}
f_{\gamma}^{V}=\frac{f_{\gamma}^{M} / \rho_{\gamma}}{f_{\gamma}^{M} / \rho_{\gamma}+f_{\beta}^{M} / \rho_{\beta}} \\
f_{\beta}^{V}=\frac{f_{\beta}^{M} / \rho_{\beta}}{f_{\gamma}^{M} / \rho_{\gamma}+f_{\beta}^{M} / \rho_{\beta}}
\end{gathered}
$$

where $\rho_{\gamma}$ and $\rho_{\beta}$ are the approximated high temperature density of the $\gamma$ and $\beta$ phase, taken as $7.83 \times 10^{3} \mathrm{~kg} / \mathrm{m}^{3}$ and $6.81 \times 10^{3} \mathrm{~kg} / \mathrm{m}^{3}$ respectively [16]. The densities, obtained by considering the atomic fraction of the elements in each phase at $1100{ }^{\circ} \mathrm{C}$ and the lattice parameter of each phase, are in good agreement with reported values in the literature [62]. The converted volume fractions agree well with experimentally measured volume fractions as summarised in Table 1, assuming phase equilibrium at $1100^{\circ} \mathrm{C}$. Fig. 3 shows EBSD-derived inverse pole figure and phase distribution maps for vacuum heat treated coating prior to isothermal heat treatment. These figures reveal that the $\gamma$ grains are generally twinned and the $\beta$ grains are monocrystalline grains in the coating. No evidence for preferred orientation was found in either $\gamma$ or $\beta$ phases. It can be seen that coarse grain regions within the particles and fine grain regions around the particle boundaries. This can be attributed to high cooling rate occurred at the particle boundaries when molten particles collide with the splats. The high impact force generated from high velocity collision can mechanically deform the splats and recrystallization occurred around the particle boundaries, causing the fine grains to form. The coarse grains were retained as the initial powder structure. Grain size ranges from $1 \sim 2 \mu \mathrm{m}$ in the coarse grain regions and about $\sim 500 \mathrm{~nm}$ or even less in the fine grain regions.

Fig. 4 illustrates the microstructure evolution of the coating after isothermal heat treatments for different time intervals at $1100{ }^{\circ} \mathrm{C}$. It can be seen that the coarsening of the $\beta$-phase occurs and the number of $\beta$-phase particles decreases from Fig. 4(a) - (d), compared to Fig. 1(b). No significant change in the volume fraction of the $\beta$ phase is found after the isothermal heat 
treatments. The $\beta$-phase particles are nearly cuboidal in morphology and some of them have serrated surfaces. These protrusions may be due to the instabilities on interfaces during growth. Since the growth of such protrusions would significantly increase the interfacial energy, it is likely that these are driven by the coalescence of $\beta$-phase particles. Indeed Fig. 4 shows the evidence of coalescence of small $\beta$-phase particles.

\section{2. $\beta$-phase coarsening kinetics}

The classical LSW coarsening theory of Ostwald ripening on the $\beta$-phase can be described as $[44,45]:$

$$
r^{3}-r_{0}^{3}=k t
$$

where $r$ and $r_{0}$ are the average particle size of $\beta$ phase at time $\mathrm{t}$ and $\mathrm{t}=0$ respectively, and $\mathrm{k}$ is the coarsening rate coefficient, can be given by Eq. (4) as the first approximation [39, 52]:

$$
k=\frac{8 D_{\mathrm{eff}} \sigma N_{\gamma} V_{m}}{9 R T}
$$

where $D_{\text {eff }}$ is the effective diffusion coefficient, $\sigma$ is the interfacial energy per unit area, $\mathrm{N}_{\gamma}$ is the total equilibrium mole fraction of alloying elements in the $\gamma$ matrix, $\mathrm{V}_{\mathrm{m}}$ is the molar volume of the $\beta$ phase, $R$ is the gas constant and $T$ is the absolute coarsening temperature. Eq. (4) only accounts the alloying elements in the matrix but does not consider the significant ranges of solubility of the alloying elements in the precipitate phase. Thus, for the case of $\gamma+\beta$ structure in this CoNiCrAlY coating, Eq (4) becomes [52, 63],

$$
k=\frac{8 D_{\mathrm{eff}} \sigma N_{\gamma}\left(1-N_{\gamma}\right) V_{m}}{9\left(N_{\beta}-N_{\gamma}\right)^{2} R T}
$$

where $\mathrm{N}_{\beta}$ is the total equilibrium mole fraction of alloying elements in the $\beta$ phase. Furthermore, the classical LSW theory was originally derived from the dilute binary alloy systems, assuming the volume fraction of secondary phases were infinitely small, which is not very suitable for the case of this CoNiCrAlY alloy due to the volume fraction of the secondary $\beta$ phase is around $30 \%$. It has been reported by Wang et al. that the volume 
fractions of the secondary phases will significant affect the coarsening rate coefficients [51]. Therefore, in order to account the effects of $\beta$-phase volume fraction on the coarsening kinetics, a dimensionless factor as a function of $\beta$-phase volume fraction $\left(f_{\beta}^{V}\right)$ is introduced by combining the models reviewed by Baldan [39] and the most recent effort by Ai et al. [50] for cubic/nearly cubic morphology of secondary phase.

$$
\mathrm{A}\left(f_{\beta}^{V}\right)=2.22+25.55 \times f_{\beta}^{V}-1.60 \times f_{\beta}^{V^{2}}+0.65 \times f_{\beta}^{V^{3}}
$$

By now, Eq. (5) can be rewritten as Eq. (7) to represent the coarsening kinetics of the $\beta$ phase in this CoNiCrAlY coating.

$$
k=\frac{8 \mathrm{~A}\left(f_{\beta}^{V}\right) D_{\mathrm{eff}} \sigma N_{\gamma}\left(1-N_{\gamma}\right) V_{m}}{9\left(N_{\beta}-N_{\gamma}\right)^{2} R T}
$$

Taken the volume fraction of the $\beta$ phase, $f_{\beta}^{V}$, as $30 \%, \mathrm{~A}\left(f_{\beta}^{V}\right)$ is calculated as 9.76 . For the compositional term, $N_{\gamma}\left(1-N_{\gamma}\right) /\left(N_{\beta}-N_{\gamma}\right)^{2}$, it can be determined from the elemental composition in each phase. Table 2 summarises the composition for $\gamma$ and $\beta$ phase calculated from the Thermo-Calc using TTNi7 database, which was proved to be consistent with the experimental phase composition in previous work [42]. Since Al is the main alloy element in the $\beta$ phase and Co is the base element in the $\gamma$ matrix, the compositional term then equals to 3 . The molar volume, $V_{m}$, of the $\beta$ phase can be calculated from Eq. (8) [64]

$$
V_{m}=\frac{a_{\beta^{3}}}{n_{\beta}} N_{0}
$$

where $a_{\beta}$ is the lattice parameter of $\beta$ phase, taken as $0.286 \mathrm{~nm}[16], a_{\beta}{ }^{3}$ represents the volume of the cubic unit cell, $n_{\beta}$ is the number of atoms in the unit cell, taken as 2 for the bcc structure and $N_{0}$ is the Avogadro number $\left(6.02 \times 10^{23} \mathrm{~mol}^{-1}\right)$. The molar volume of the $\beta$ phase is found to be $7.04 \times 10^{-6} \mathrm{~m}^{3} / \mathrm{mol}$, which agrees well with the range $7.0 \times 10^{-6} \sim 7.8 \times 10^{-6} \mathrm{~m}^{3} / \mathrm{mol}$ for $\beta$-NiAl alloy proposed by Paul et al. [64].

Since $\mathrm{Al}$ is the dominant solute during the $\beta$-phase coarsening, the diffusion coefficient of $\mathrm{Al}$ is thus used to represent the effective diffusion coefficient, $\mathrm{D}_{\text {eff }}$, when calculating the 
coarsening rate coefficient. Considering the limited diffusion data available in the $\beta$ phase, the Al diffusion coefficient in the fcc- $\gamma$ matrix is employed here as the first attempt, which obeys the Arrhenius relationship as follows,

$$
D_{\mathrm{eff}}=D_{0} \exp \left(-\frac{Q}{R T}\right)
$$

where $\mathrm{D}_{0}$ and $\mathrm{Q}$ are the frequency factor and activation energy respectively. Taken the diffusion data from Karunaratne et al. [31], $\mathrm{D}_{\text {eff }}$ is found to be $1.19 \times 10^{-14} \mathrm{~m}^{2} / \mathrm{s}$. The magnitude falls into the right range of the previously reported work [29, 42]. It has to be emphasised that the $\mathrm{D}_{\text {eff }}$ used here may not be the exact effective diffusion coefficient in this CoNiCrAlY alloy, but only as the first approximation.

\subsection{Interfacial energy}

In addition to $D_{\text {eff }}$, one of the main parameters in Eq. (7) is the interfacial energy, $\sigma$, which is usually obtained by back-calculation from the experimental coarsening data [54]. But $\sigma$ can also be mathematically achieved by considering it as a function of a chemical component in the alloy system [52]. In its basic form, the interfacial energy is directly proportional to the enthalpy of the alloy, which can be expressed as [65],

$$
\sigma=\frac{z^{*} N^{*}}{z N_{0}} \Delta H_{m}
$$

where $\mathrm{z}^{*}$ and $\mathrm{z}$ are the number of atoms per unit area of the interface and the coordination number of nearest neighbours in the lattice respectively. It has been found by Sonderegger et al. that $\mathrm{z}^{*} / \mathrm{z}=0.329$ in fcc and bcc structures based on the nearest-neighbour broken-bond analysis [65]. $\mathrm{N}^{*}$ is the number of cross bonds per atom at the interface and can be determined using the relation of

$$
N^{*}=4^{2 / 3} / a^{2}
$$

where $a$ is the effective lattice constant, taken as $a=\left(a_{\gamma}+a_{\beta}\right) / 2$. The lattice parameters of $\gamma$ phase $\left(a_{\gamma}\right)$ and $\beta$ phase $\left(a_{\beta}\right)$ are found to be $0.356 \mathrm{~nm}$ and $0.286 \mathrm{~nm}$ respectively from X-ray 
diffraction analysis [16]. $\Delta H_{m}$ is the enthalpy of solution of 1 mole of $\beta$ phase in the $\gamma$ matrix in equilibrium at the coarsening temperature. The enthalpy can be obtained from Thermo-Calc using the TTNi7 thermodynamic database and the interfacial energy can then be mathematically determined, as shown in Fig. 5(a) and (b) respectively. The large interfacial energy in this $\gamma / \beta$ structure can be attributed to several factors. The well-ordered B2 bcc- $\beta$ phase [62] has a different crystal structure compared to the fcc- $\gamma$ matrix, which is likely to produce an incoherent interface. The different compositions in $\gamma$ and $\beta$ phase shown in Table 2 further support that the $\gamma / \beta$ interfaces are incoherent. The large size and serrated surfaces of the $\beta$-phase particles, seen in Fig. 4, can also increase the interfacial energy of the incoherent interface. The net effect of the above could be the large interfacial energy of this CoNiCrAlY alloy as it is indeed shown in Fig. 5(b).

In order to show the reliability of this methodology in calculating the interfacial energy, a comparison was conducted between the reported values and calculated result by Eq. (10) for $\sigma$. Due to the limited data available for MCrAlY alloys, direct comparison was not possible. However, it was reported that the interfacial energies for Fe-Ni-Al and Fe-Ni-Al-Mo with bcc-NiAl as precipitate are $20-40 \mathrm{~mJ} / \mathrm{m}^{2}$ at $700{ }^{\circ} \mathrm{C}[66,67]$. These two alloys have the bcc ferritic phase, thus a high coherency is possible. But the $\gamma / \beta$ interface is incoherent in this CoNiCrAlY alloy and the interfacial energy is partially dependent on the temperature, thus the interfacial energy is expected to be larger in this study at $1100^{\circ} \mathrm{C}$. Reference values for $\mathrm{Ni}$ superalloys with $\gamma / \gamma^{\prime}$ structure and Ti alloys with $\alpha / \beta$ structure were also considered. It is generally found that the interfacial energies for Ni superalloys are $50-140 \mathrm{~mJ} / \mathrm{m}^{2}$, varying with composition and temperature $[52,65]$. The $\gamma / \gamma^{\prime}$ morphology in Ni superalloys is quite different from the $\gamma / \beta$ morphology in the CoNiCrAlY coating used here, and the stabilising minor elements added in Ni superalloys, such as Mo, Re, Ta, and W, can also reduce the $\gamma / \gamma^{\prime}$ interfacial energy. But the protrusions of $\beta$-phase shown in Fig. 4 indicate that the alloy exhibits high interfacial energies. Similar findings were reported by Xu et al. [54] in a $\alpha / \beta \mathrm{Ti}$ 
alloys, where overall morphology of the secondary phase is close to the $\beta$ phase reported in this work. It is suggested that interfacial energy for such $\alpha / \beta$ structure lies in the range of 200$400 \mathrm{~mJ} / \mathrm{m}^{2}$ in their study, which is consistent with the interfacial energy shown in Fig. 5. The irregular shapes of the $\beta$ phase shown in Fig. 4 further support the high interfacial energy in this CoNiCrAlY coating.

\subsection{Coarsening rate coefficient}

All the parameters determined for Eq. (7) are summarised in Table 3 and the comparison of the $\beta$-phase coarsening behaviour of Eq. (3) is presented in Fig. 6. The coarsening rate coefficient obtained from experimental measurements is $6.49 \times 10^{-5} \mu \mathrm{m}^{3} / \mathrm{s}$ when $r_{0}=1.5 \mu \mathrm{m}$, which exhibits good agreement with the value calculated in Table 3. Due to the difficulties in identifying individual particles in image processing and the coalescence of small $\beta$-phase particles, the accurate quantitative measurement of $\beta$-phase particle size from micrographs is challenging and prone to much error. It is assumed that the $\beta$-phase particles remain cuboidal during growth/dissolution/coalescence in this work. Measurements of the $\beta$-phase areas were performed from SEM micrographs and an equivalent particle size was calculated by equating the measured particle area to that of a square of equivalent area. Fig. 4 shows the various sizes and morphologies of the $\beta$ phase, this could produce large discrepancies in measurements. The $\beta$-phase coalescence can significantly increase the particle size, thus large error was resulted. Since the particle coalescence was not accounted in the modified LSW theory, the calculated coarsening rate coefficient could be smaller than experimentally determined value. The implication and mechanism of particle coalescence is to be discussed in a separate paper. Nevertheless, the coarsening rate coefficients obtained in Fig. 6 lie in the similar range of the work reported by $\mathrm{Li}$ et al. for the Alloy Nimonic 115 at $1100{ }^{\circ} \mathrm{C}$ [52]. It is also worth noting that discrete oxide particles and thin oxide stringers have formed during HVOF spraying, these micro-sized, non-diffusional oxides can act as diffusion barriers which could tie up the $\beta$ 
phase particles and allow large particles to form [68]. As a consequence, larger coarsening rate coefficient was obtained from experimental measurements.

\section{Conclusions}

- Microstructural characterisation reveals a two phase structure in the HVOF sprayed CoNiCrAlY coating, with a twinned $\gamma$ grain structure and a monocrystalline structure of $\beta$ phase at grain sizes varying largely from $2 \mu \mathrm{m}$ to $\sim 0.5 \mu \mathrm{m}$ or even less. The $\beta$ phase exhibits cuboidal morphology and protrusions of the $\beta$-phase particles are found to exist due to the high interfacial energy $\left(262.64 \mathrm{~mJ} / \mathrm{m}^{2}\right)$ of the $\beta$ phase.

- It is found that $\beta$-phase particle sizes in this CoNiCrAlY coating increase with heat treatment time. The volume-diffusion-controlled $\beta$-phase coarsening behaviour is found to follow $r^{3}-r_{0}^{3}$ versus $t$ kinetics and the coarsening rate coefficient determined from experimental measurements is $6.49 \times 10^{-5} \mathrm{\mu m}^{3} / \mathrm{s}$ at $1100{ }^{\circ} \mathrm{C}$.

- A volume fraction incorporated analytical coarsening model is established to calculate the coarsening rate coefficient of $\beta$ phase by considering the composition, interfacial energy and effective diffusion coefficient in the CoNiCrAlY alloy at $1100{ }^{\circ} \mathrm{C}$, with the aid of thermodynamics software Thermo-Calc using the TTNi7 thermodynamic database.

- The experimentally determined coarsening rate coefficient agrees well with the mathematically calculated value $\left(5.02 \times 10^{-5} \mathrm{\mu m}^{3} / \mathrm{s}\right)$ at $1100{ }^{\circ} \mathrm{C}$. Discrepancies may be attributed to the inaccuracy in mathematical calculations, instability in measuring the $\beta$-phase particle size, the coalescence of small $\beta$ phases and the oxides embedded in the coating during HVOF spraying.

\section{Acknowledgements}


The authors would like to take this opportunity to thank Prof. John Nicholls from Cranfield University for helpful discussions. The authors would like to acknowledge Faculty of Engineering, University of Nottingham for provision of laboratory facilities. We would also like to thank Loughborough University and Dr. G. West for assistance with the EBSD study. The financial support from Nature Science Foundation of China (No. 21403119), Zhejiang Natural Science Foundation Programme (No. LQ16E060001), Zhejiang Commonweal Technology Project (No. 2016C31023), Ningbo Enrich People Project (2016C10035) and Ningbo Natural Science Foundation Programme (No. 2016A610114) are acknowledged.

\section{References}

[1] G.W. Goward, Surf. Coat. Technol., 108-109 (1998) 73-79.

[2] J.R. Nicholls, JOM, 52 (2000) 28-35.

[3] D. Stöver, C. Funke, J. Mater. Process. Technol., 92-93 (1999) 195-202.

[4] A.G. Evans, D.R. Mumm, J.W. Hutchinson, G.H. Meier, F.S. Pettit, Prog. Mater. Sci., 46 (2001) 505-553.

[5] D. Kumar, K.N. Pandey, D.K. Das, Int. J. Miner. Metall. Mater., 23 (2016) 934-942.

[6] C.U. Hardwicke, Y.-C. Lau, J. Therm. Spray Technol., 22 (2013) 564-576.

[7] H. Chen, T.H. Hyde, Mater. Sci. Eng. A, 680 (2017) 203-209.

[8] S. Li, X. Yang, H. Qi, G. Xu, D. Shi, Mater. Sci. Eng. A, 678 (2016) 57-64.

[9] J. Toscano, R. Vaen, A. Gil, M. Subanovic, D. Naumenko, L. Singheiser, W.J. Quadakkers, Surf. Coat. Technol., 201 (2006) 3906-3910.

[10] A. Gil, V. Shemet, R. Vassen, M. Subanovic, J. Toscano, D. Naumenko, L. Singheiser, W.J. Quadakkers, Surf. Coat. Technol., 201 (2006) 3824-3828.

[11] S. Saeidi, K.T. Voisey, D.G. McCartney, J. Therm. Spray Technol., 18 (2009) 209-216.

[12] C.S. Richard, G. Béranger, J. Lu, J.F. Flavenot, Surf. Coat. Technol., 82 (1996) 99-109.

[13] M. Okazaki, S. Yamagishi, Y. Yamazaki, K. Ogawa, H. Waki, M. Arai, Int. J. Fatigue, 53 (2013) 33-39.

[14] H. Chen, D.G. McCartney, K.T. Voisey, Mater. High Temp., 32 (2015) 215-220.

[15] H. Chen, T.H. Hyde, K.T. Voisey, D.G. McCartney, Mater. Sci. Eng. A, 585 (2013) 205213.

[16] H. Chen, Mechanical and chemical behaviour of thermally sprayed CoNiCrAlY bond coats, Ph.D Thesis, Department of Mechanical, Materials and Manufacturing Engineering, University of Nottingham, (2015).

[17] H. Chen, T.H. Hyde, K.T. Voisey, D.G. McCartney, Proc IMechE Part L: J Materials: Design and Application, DOI 10.1177/1464420715622495 (2016).

[18] W. Brandl, D. Toma, H. Grabke, Surf. Coat. Technol., 108 (1998) 10-15.

[19] P. Puetz, X. Huang, R.S. Lima, Q. Yang, L. Zhao, Surf. Coat. Technol., 205 (2010) 647657.

[20] J. Toscano, D. Naumenko, A. Gil, L. Singheiser, W.J. Quadakkers, Mater. Corros., 59 (2008) 501-507.

[21] P. Poza, P.S. Grant, Surf. Coat. Technol., 201 (2006) 2887-2896. 
[22] D. Naumenko, V. Shemet, L. Singheiser, W. Quadakkers, J. Mater. Sci., 44 (2009) 16871703.

[23] T. Koomparkping, S. Damrongrat, P. Niranatlumpong, J. Therm. Spray Technol., 14 (2005) 264-267.

[24] P. Fox, G.J. Tatlock, Mater. Sci. Technol., 5 (1989) 816-827.

[25] N. Czech, F. Schmitz, W. Stamm, Surf. Coat. Technol., 76-77 (1995) 28-33.

[26] H. Chen, D.G. McCartney, Surf. Coat. Technol., DOI

http://dx.doi.org/10.1016/j.surfcoat.2017.01.075 (2017).

[27] D. Kumar, K.N. Pandey, D.K. Das, Mater. Today Proc., 2 (2015) 3156-3160.

[28] C.E. Lowell, C.A. Barrett, R.W. Palmer, J.V. Auping, H.B. Probst, Oxid. Met., 36 (1991) 81-112.

[29] E.Y. Lee, D.M. Chartier, R.R. Biederman, R.D. Sisson, Surf. Coat. Technol., 32 (1987) 19-39.

[30] D.R.G. Achar, R. Munoz-Arroyo, L. Singheiser, W.J. Quadakkers, Surf. Coat. Technol., 187 (2004) 272-283.

[31] M.S.A. Karunaratne, S.L. Ogden, S.D. Kenny, R.C. Thomson, Mater. Sci. Technol., 25 (2009) 287-299.

[32] R. Pillai, W.G. Sloof, A. Chyrkin, L. Singheiser, W.J. Quadakkers, Mater. High Temp., 32 (2015) 57-67.

[33] K. Yuan, R. Eriksson, R. Lin Peng, X.-H. Li, S. Johansson, Y.-D. Wang, Surf. Coat. Technol., 232 (2013) 204-215.

[34] R. Eriksson, K. Yuan, X.-H. Li, R. Lin Peng, Surf. Coat. Technol., 253 (2014) 27-37.

[35] K. Yuan, R. Lin Peng, X.-H. Li, S. Johansson, Y.-D. Wang, Surf. Coat. Technol., 261 (2015) 86-101.

[36] M.S.A. Karunaratne, I. Di Martino, S.L. Ogden, D.L. Oates, R.C. Thomson, Metall. Mater. Trans. A, 43 (2011) 774-788.

[37] K. Yuan, R. Eriksson, R. Lin Peng, X.-H. Li, S. Johansson, Y.-D. Wang, Surf. Coat. Technol., 254 (2014) 79-96.

[38] M. Elsaß, M. Frommherz, A. Scholz, M. Oechsner, Surf. Coat. Technol., 307, Part A (2016) 565-573.

[39] A. Baldan, J. Mater. Sci., 37 (2002) 2171-2202.

[40] Q.M. Wang, H. Li, M.H. Guo, P.L. Ke, J. Gong, C. Sun, L.S. Wen, Mater. Sci. Eng. A, 406 (2005) 350-357.

[41] K.J. Hemker, B.G. Mendis, C. Eberl, Mater. Sci. Eng. A, 483-484 (2008) 727-730.

[42] H. Chen, G.A. Jackson, K.T. Voisey, D.G. McCartney, Surf. Coat. Technol., 291 (2016) 34-42.

[43] M.K. Chen, P.W. Voorhees, Modell. Simul. Mater. Sci. Eng., 1 (1993) 591-612.

[44] I.M. Lifshitz, V.V. Slyozov, J. Phys. Chem. Solids, 19 (1961) 35-50.

[45] C. Wagner, Z. Electrochem, 65 (1961) 581-591.

[46] T. Philippe, P.W. Voorhees, Acta Mater., 61 (2013) 4237-4244.

[47] F. Masoumi, M. Jahazi, D. Shahriari, J. Cormier, J. Alloys Compd., 658 (2016) 981-995.

[48] H. Basoalto, M. Anderson, Acta Mater., 117 (2016) 122-134.

[49] M.J. Anderson, A. Rowe, J. Wells, H.C. Basoalto, Acta Mater., 114 (2016) 80-96.

[50] C. Ai, X. Zhao, J. Zhou, H. Zhang, L. Liu, Y. Pei, S. Li, S. Gong, J. Alloys Compd., 632 (2015) 558-562.

[51] T. Wang, G. Sheng, Z.-K. Liu, L.-Q. Chen, Acta Mater., 56 (2008) 5544-5551.

[52] X. Li, N. Saunders, A.P. Miodownik, Metall. Mater. Trans. A, 33 (2002) 3367-3373.

[53] J. Xu, W. Zeng, X. Sun, Z. Jia, J. Zhou, J. Alloys Compd., 631 (2015) 248-254.

[54] J. Xu, W. Zeng, Z. Jia, X. Sun, J. Zhou, J. Alloys Compd., 618 (2015) 343-348.

[55] J. Li, C. Guo, Y. Ma, Z. Wang, J. Wang, Acta Mater., 90 (2015) 10-26.

[56] D.A. Shnawah, M.F.M. Sabri, I.A. Badruddin, S.B.M. Said, M.B.A. Bashir, N.M. Sharif, M.H. Elsheikh, J. Alloys Compd., 622 (2015) 184-188. 
[57] K. Miao, Y. He, N. Zhu, J. Wang, X. Lu, L. Li, J. Alloys Compd., 622 (2015) 513-523. [58] Y. Zhang, K. Gao, S. Wen, H. Huang, Z. Nie, D. Zhou, J. Alloys Compd., 610 (2014) 27-34.

[59] S. Saeidi, K.T. Voisey, D.G. McCartney, J. Therm. Spray Technol., 20 (2011) 1-13.

[60] C.A. Schneider, W.S. Rasband, K.W. Eliceiri, Nat. Methods, 9 (2012) 671-675.

[61] K.V. Dahl, J. Hald, A. Horsewell, Defect and Diffusion Forum, 258-260 (2006) 73-78.

[62] R.D. Noebe, R.R. Bowman, M.V. Nathal, Int. Mater. Rev., 38 (1993) 193-232.

[63] H.A. Calderon, P.W. Voorhees, J.L. Murray, G. Kostorz, Acta Metall. Mater., 42 (1994) 991-1000.

[64] A. Paul, A.A. Kodentsov, F.J.J. van Loo, J. Alloys Compd., 403 (2005) 147-153.

[65] B. Sonderegger, E. Kozeschnik, Metall. Mater. Trans. A, 40 (2009) 499-510.

[66] H.A. Calderon, M.E. Fine, Mat. Sci. Eng., 63 (1984) 197-208.

[67] H.A. Calderon, M.E. Fine, J.R. Weertman, MTA, 19 (1988) 1135-1146.

[68] H. Peng, H. Guo, J. He, S. Gong, J. Alloys Compd., 502 (2010) 411-416. 
Table 1

Comparison of $\gamma$ and $\beta$ phase fractions between experimental measurements and calculated values using Thermo-Calc with the TTNi7 database at $1100{ }^{\circ} \mathrm{C}$

\begin{tabular}{c|c|c|c|c}
\hline \multirow{2}{*}{} & \multicolumn{2}{|c|}{ Phase mass fraction } & \multicolumn{2}{c}{ Phase volume fraction } \\
\cline { 2 - 5 } & $\gamma$ & $\beta$ & $\gamma$ & $\beta$ \\
\hline TTNi7 & $75 \%$ & $25 \%$ & $72 \%$ & $28 \%$ \\
Calculated & ---- & ---- & $69 \pm 2 \%$ & $30 \pm 2 \%$ \\
\hline $\begin{array}{c}\text { Experimental } \\
\text { measurements }\end{array}$ & & & & \\
\hline
\end{tabular}


Table 2

$\gamma$ and $\beta$ phase compositions of CoNiCrAlY (Co-31.7Ni-20.8Cr-8.1Al-0.5Y, all in wt\%, neglecting Y) calculated from Thermo-Calc using the TTNi7 database at $1100{ }^{\circ} \mathrm{C}$.

\begin{tabular}{|c|c|c|c|c|c|}
\hline \multirow{2}{*}{\multicolumn{2}{|c|}{ Element }} & \multicolumn{2}{|c|}{$\gamma$ phase } & \multicolumn{2}{|c|}{$\beta$ phase } \\
\hline & & wt $\%$ & at $\%$ & wt $\%$ & at $\%$ \\
\hline \multirow{4}{*}{$\begin{array}{c}\text { Calculated } \\
\text { TTNi7 } \\
\text { (at } 1100^{\circ} \mathrm{C} \text { ) }\end{array}$} & Co & 43.0 & 39.4 & 28.6 & 23.2 \\
\hline & $\mathrm{Ni}$ & 27.4 & 25.2 & 44.8 & 36.6 \\
\hline & $\mathrm{Cr}$ & 24.9 & 25.9 & 8.4 & 7.7 \\
\hline & $\mathrm{Al}$ & 4.8 & 9.5 & 18.3 & 32.4 \\
\hline
\end{tabular}


Table 3

Calculated dimensionless volume fraction factor $\mathrm{A}\left(\boldsymbol{f}_{\boldsymbol{\beta}}^{V}\right)$, the compositional term $N_{\gamma}\left(1-N_{\gamma}\right) /\left(N_{\beta}-N_{\gamma}\right)^{2}$, the molar volume of $\beta$ phase $V_{m}$, the effective diffusion coefficient $D_{\text {eff }}$, the interfacial energy $\sigma$ and the coarsening rate coefficient $k$ of CoNiCrAIY (Co-31.7Ni-20.8Cr-8.1Al-0.5Y, all in wt\% $)$ at $1100{ }^{\circ} \mathrm{C}$.

\begin{tabular}{|c|c|c|c|c|c|c|}
\hline$f_{\beta}^{V}$ & $\mathrm{~A}\left(f_{\beta}^{V}\right)$ & $N_{\gamma}\left(1-N_{\gamma}\right) /\left(\mathrm{N}_{\beta}-\mathrm{N}_{\gamma}\right)^{2}$ & $\begin{array}{c}V_{m} \\
\left(\mathrm{~m}^{3} / \mathrm{mol}\right)\end{array}$ & $\begin{array}{c}D_{\text {eff }} \\
\left(\mathrm{m}^{2} / \mathrm{s}\right)\end{array}$ & $\begin{array}{c}\sigma \\
\left(\mathrm{mJ} / \mathrm{m}^{2}\right)\end{array}$ & $\begin{array}{c}k \\
\left(\mu \mathrm{m}^{3} / \mathrm{s}\right)\end{array}$ \\
\hline 0.30 & 9.76 & 3.00 & $7.04 \times 10^{-6}$ & $1.19 \times 10^{-14}$ & 262.64 & $5.02 \times 10^{-5}$ \\
\hline
\end{tabular}




\section{Figures}

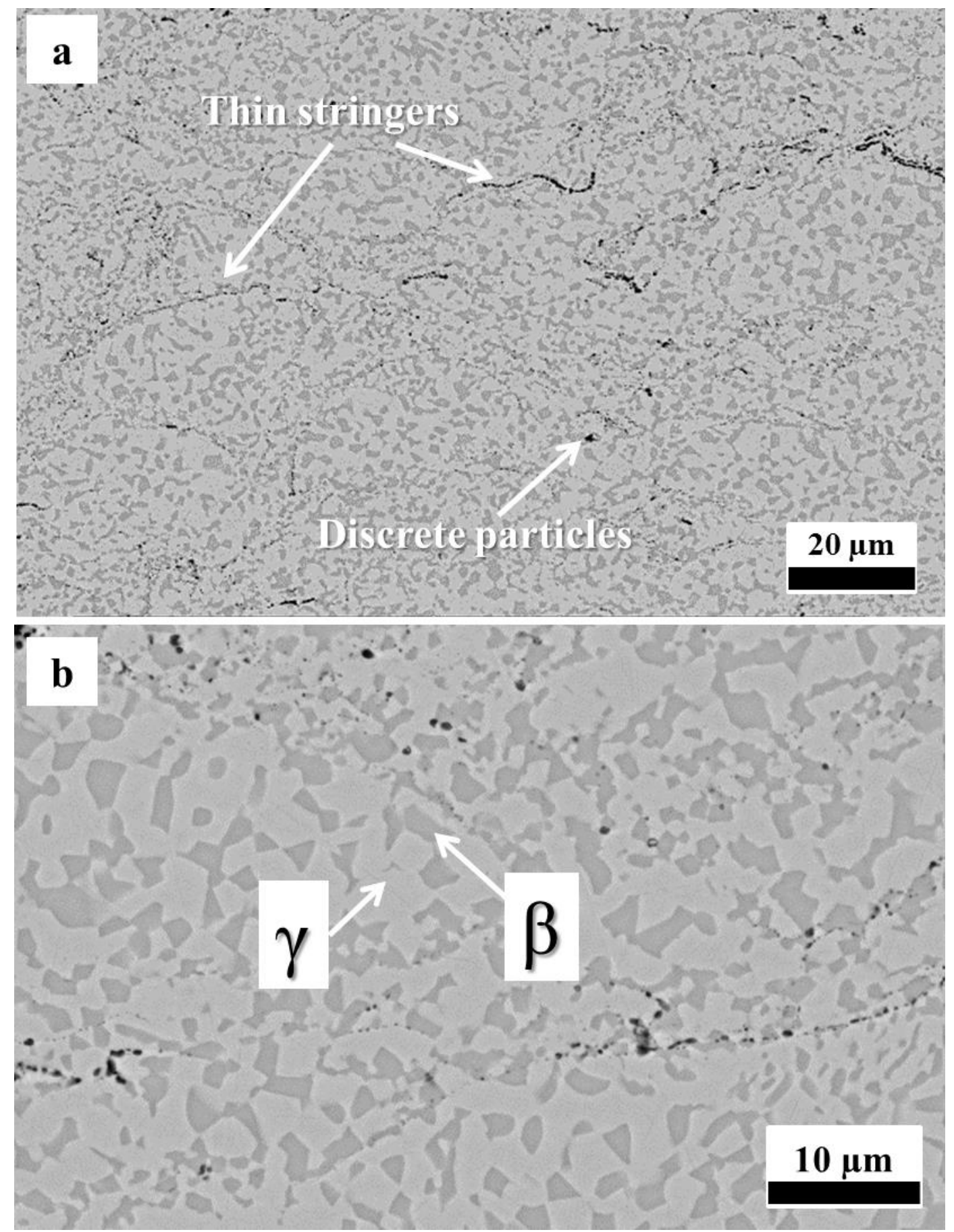

Fig. 1. Microstructure of vacuum heat-treated HVOF CoNiCrAlY coating at $1100{ }^{\circ} \mathrm{C}$ for $2 \mathrm{~h}$,

(a) low magnification and (b) high magnification. 


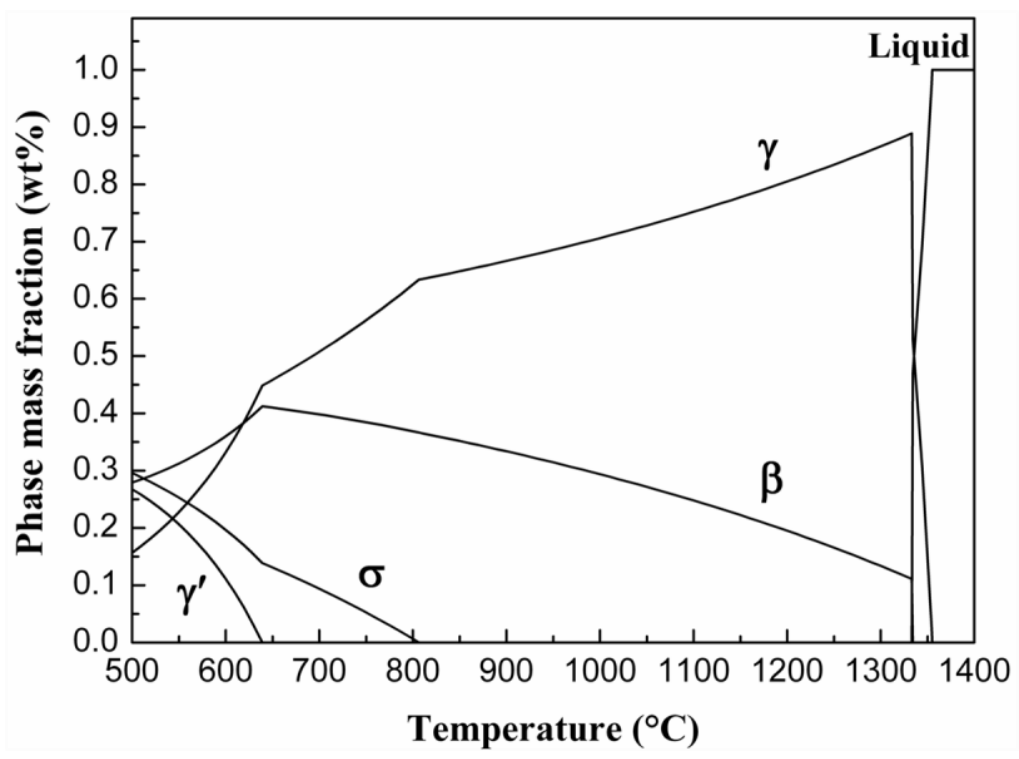

Fig. 2. Plot of phase mass fraction versus temperature obtained from Thermo-Calc using TTNi7 database.
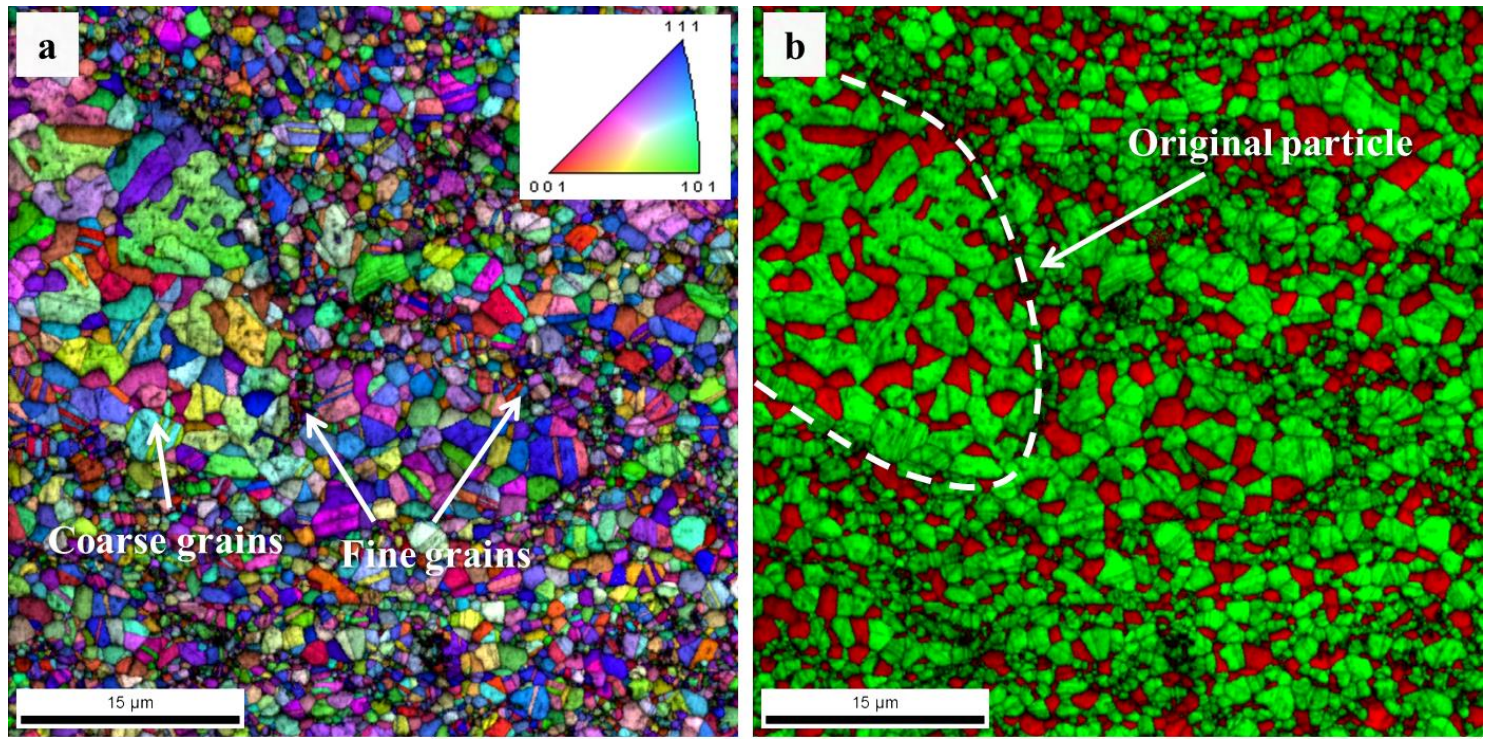

Fig. 3. EBSD-derived inverse pole figure map (a) and phase distribution map (b) for vacuum heat treated CoNiCrAlY coating. The $\beta$-phase is coloured red and the $\gamma$-phase is coloured green in (b). 

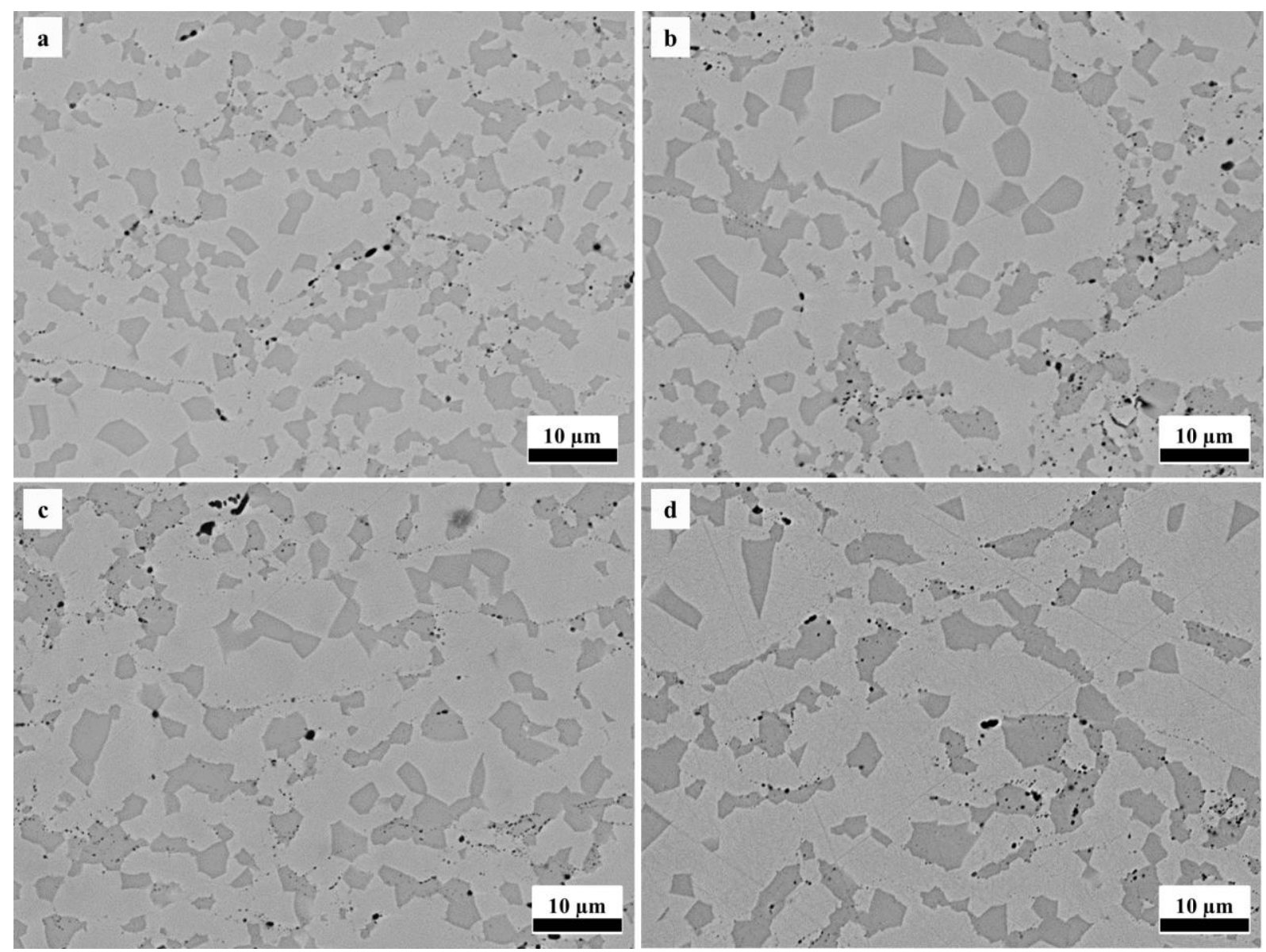

Fig. 4. SEM micrographs of material heat treated for (a) $50 \mathrm{~h}$, (b) $75 \mathrm{~h}$, (c) $100 \mathrm{~h}$ and (d) 250 h at $1100^{\circ} \mathrm{C}$. 

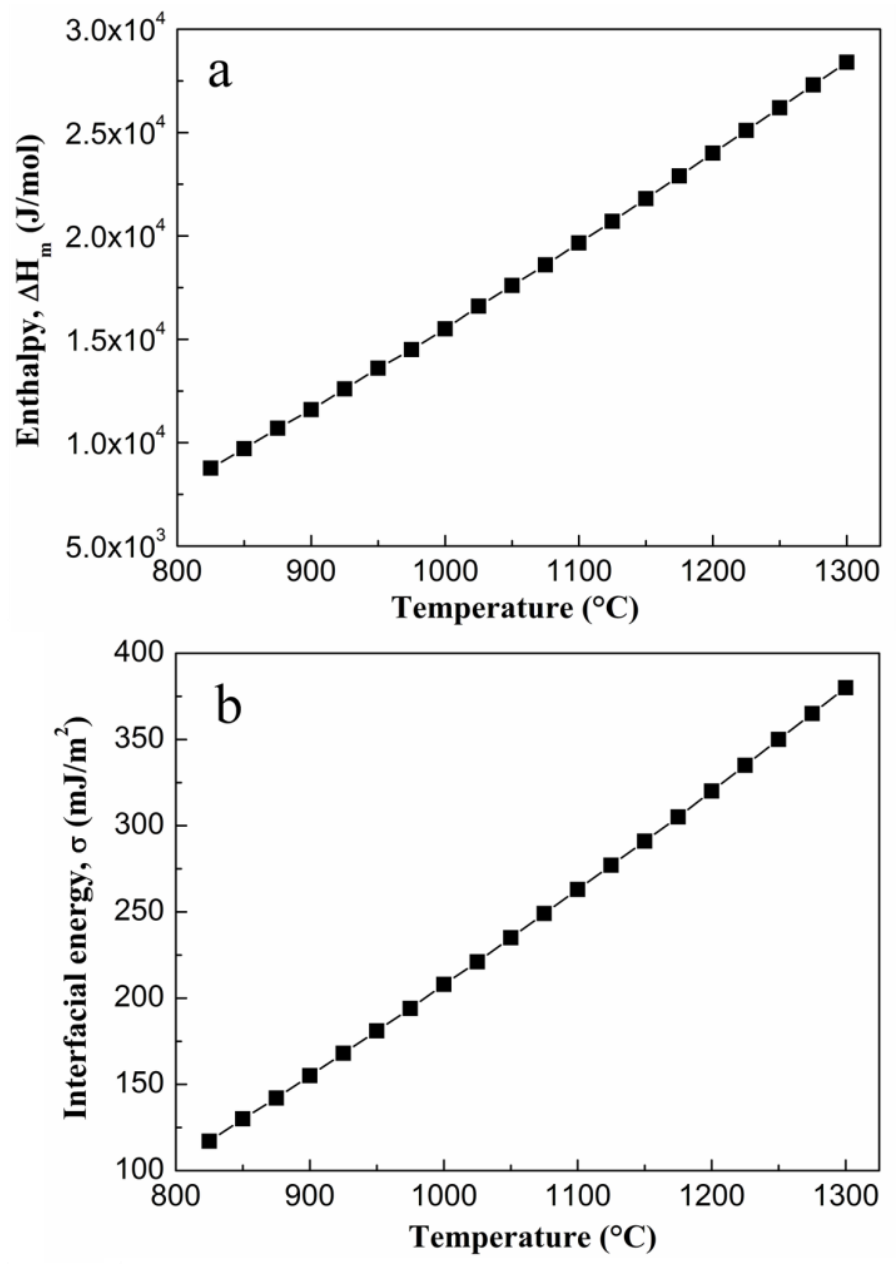

Fig. 5. Plots of Enthalpy versus temperature obtained from Thermo-Calc using TTNi7 database (a) and calculated interfacial energy versus temperature (b).

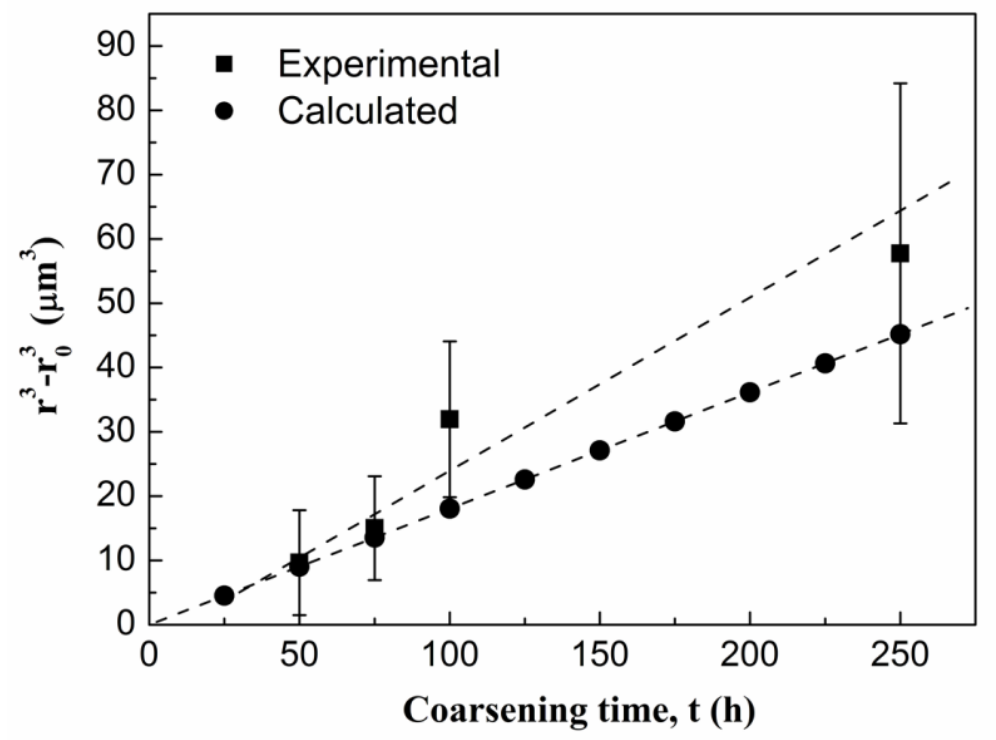

Fig. 6. Plot of the calculated and experimentally measured $\beta$-phase coarsening behaviour according to Eq. (3) at $1100{ }^{\circ} \mathrm{C}$. 